\title{
The Relationship among Cost-Reducing R\&D Investment, Occupational Choice, and Trade
}

\author{
Tadashi Morita \\ Faculty of Economics, Kindai University, Osaka, Japan \\ Email: t-morita@kindai.ac.jp
}

Received 20 October 2014; revised 29 November 2014; accepted 13 December 2014

Copyright (C) 2014 by author and Scientific Research Publishing Inc.

This work is licensed under the Creative Commons Attribution International License (CC BY). http://creativecommons.org/licenses/by/4.0/

c. (i) Open Access

\begin{abstract}
In this paper, I construct a two-country model in which oligopolistic firms export goods and undertake cost-reducing R\&D investment. In this model, abilities of individual to become skilled worker are heterogeneous and they choose to become skilled worker or unskilled worker. Individuals have to incur the cost of education in order to become skilled workers. Each country imposes tariffs. When the cost of education is sufficiently high, a decrease in the tariff rate decreases the level of R\&D investment. However, when the cost of education is sufficiently small, a decrease in the tariff rate increases the level of $R \& D$ investment.
\end{abstract}

\section{Keywords}

R\&D, Occupational Choice, Trade, Oligopoly

\section{Introduction}

In recent decades, there are three facts of economic activities, trade liberalization, an increase in R\&D investment, and the wage gap between skilled workers and unskilled workers. Wacziarg and Welch (2008) [1] showed that the number of countries having open trade policy increased from $22 \%$ of all countries in 1960 to $46 \%$ in $2000^{1}$. Second, over the last two decades, R\&D investment has increased sharply and the wage gap between skilled and unskilled workers has widened sharply. Using data for the US, the ratio of industrial R\&D expenditures to GDP increased from about $1 \%$ in 1979 to $1.43 \%$ in 1990 and $1.7 \%$ in 2004 . Third fact is that the wage gap between skilled and unskilled workers has increased in many countries recently. Acemoglu (2002) [2] pointed out that percentage of US workers with a college education increased sharply from 6\% in 1939 to 28\%

${ }^{1}$ A definition of open trade policy is provided by Sachs and Warner (1995) [3]. They defined that a country is classified as closed if it displayed at least one of the following five charasteristics; average tariff rates of $40 \%$ of more, nontariff barriers covering $40 \%$ or more, a black market exchange rate at least $20 \%$ lower than the official exchange rate, a state monopoly on major exports, and a socialist economic system. 
in 1996. He also pointed out that in the US, the college premium increased from about 0.4 in 1980 to about 0.6 in 1995.

On the basis of the above data, this paper has three objectives. First, this paper investigates the relationship between the level of cost-reducing R\&D investment and trade liberalization. When trade liberalization occurs, do firms increase the level of R\&D investment? Few papers investigate the relationship between R\&D investment and trade liberalization empirically. Funk (2003) [4] concluded that US manufacturing firms that sell their product to the US market decrease their R\&D investment when trade liberalization occurs. However, US manufacturing firms with foreign sales increase their R\&D investment. Scherer and Keun (1992) [5] showed that average US high-tech firms reduce their R\&D investment in the short run when trade liberalization occurs.

The second and third objectives of this paper are to consider whether the number of skilled workers and the wage gap between skilled and unskilled workers increases or not when trade liberalization occurs. Many researchers have investigated the relationship between the wage gap and trade liberalization. Wood (1994) [6], Leamer (1996) [7] and Kurokawa (2010) [8] argued that there was positive relationship between the wage gap and trade liberalization. However, when trade liberalization occurs, does the wage gap between skilled and unskilled workers widen and does the number of skilled workers increase?

In this paper, I construct a two-country model in which oligopolistic firms export goods and undertake costreducing R\&D investment. The governments of the countries impose tariffs on imported goods. Abilities of individuals are heterogeneous. Individuals choose to become skilled workers by paying the cost of education or remain unskilled workers, which involves no cost. In Braun (2008) [9] and Morita (2012) [10], there are two types of workers: skilled workers and unskilled workers. However, the numbers of skilled and unskilled workers are exogenously given. In this paper, the number of skilled workers is determined endogenously through the individual's choice.

I obtain two results regarding the relationship between the tariff rate and the level of R\&D investment. One is that a decrease in the tariff rate reduces the level of $R \& D$ investment when the cost of education is sufficiently high. However, a decrease in the tariff rate raises the level of R\&D investment when the cost of education is sufficiently low. This paper also shows that a decrease in the tariff rate increases the wage gap between skilled and unskilled workers when the cost of education is sufficiently high. When the cost of education is sufficiently low, the effect of decreasing the tariff rate on the wage gap is ambiguous. Furthermore, this paper shows that a decrease in the tariff rate increases the number of skilled workers when the cost of education is sufficiently high. When the cost of education is sufficiently low, the relationship between trade liberalization and the number of skilled workers is ambiguous.

Many papers have investigated the relationship between trade liberalization and cost-reducing R\&D investment. Braun (2008) [9] and Haaland and Kind (2008) [11] constructed a simple model of international oligopoly. In their papers, consumers were homogeneous agents and they did not consider the labor market for simplification. The result of these papers illustrated that trade liberalization increased R\&D investment. In contrast with these papers, Morita (2012) [10] constructed a model by incorporating the labor market into the model of Braun (2008) [9] and Haaland and Kind (2008) [11]. I showed that trade liberalization decreased R\&D investment. Compared to these researches, in this paper, the cost of education determines the effects of trade liberalization on the level of R\&D investment. Then, this paper summarizes the results of these papers.

Other related papers including Long, Raff and Stähler (2011) [12] constructed the model with heterogeneous firms and investigated the relationship between innovation and trade liberalization. Compared with my model, they assumed that R\&D outcome was stochastic. Therefore, some firms export and other firms may not produce at all. They concluded that when trade costs are high (low), trade liberalization decreases (increases) R\&D investment. Costantini and Melitz (2008) [13] and Atkeson and Burstein (2010) [14] also studied the relationship between innovation and trade liberalization with heterogeneous firms.

The remainder of this paper is organized into four sections. The next section presents the basic structure of the model. Section 3 obtains the equilibrium condition of this model. I conclude in Section 4.

\section{The Model}

There are two countries, Home and Foreign, indexed by $l \in\{H, F\}$ and these countries are symmetric. The population size in each country is equal to $L$. There are two types of workers; skilled and unskilled. Individuals choose to become either a skilled or an unskilled worker. This determines the number of skilled and unskilled 
workers. There are two types of goods, $X$ and $Y$. Good $X$ is chosen to be the numeraire. Good $X$ and good $Y$ can be produced in both countries. The firm producing good $Y$ in the Home country is named Firm $H$. The firm producing good $Y$ in the Foreign country is named Firm $F$. I assume that Firm $H$ and Firm $F$ compete strategically by using their product quantities, that is, they engage in Cournot competition. The governments of both countries levy tariffs on their imports of good $Y$ and the tariff rate is denoted by $\tau$.

\subsection{Individual}

The utility function of individual $i$ in each country is given by

$$
U^{i, l}\left(q_{i, l}, x_{i, l}\right)=x_{i, l}+a q_{i, l}-\frac{b}{2} q_{i, l}^{2}, \quad l \in\{H, F\}, \quad i \in\{0,1\}
$$

where $x_{i, l}$ is consumption of good $X$ in country $l$ by individual $i, q_{i, l}$ is consumption of good $Y$, and $a$ and $b$ are positive parameters, following Morita (2012) [10]. The budget constraint of consumer $i$ in country $l$ is as follows:

$$
x_{i, l}+p_{l} q_{i, l}=E_{i, l}, \quad l \in\{H, F\}
$$

where $p_{l}$ is the price of good $Y$, and $E_{i, l}$ is expenditure in country $l$ by consumer $i$. I assume that the price of good $X$ is unity. From the first-order condition of the individual, I obtain the following inverse demand function:

$$
\begin{aligned}
p_{L} & =a-b q_{i, l} \\
& =a-b q_{L},
\end{aligned}
$$

where $q_{l}$ denotes the average consumption level of good $Y$ in country $l$. Therefore, the inverse demand function in country $l$ is as follows:

$$
p_{l}=a-b \frac{Q_{l}}{L}
$$

where $Q_{l}$ denotes the aggregate consumption level of good $Y$ in country $l$ and $L$ represents the population size in both countries.

\subsection{Occupational Choice}

I assume that individuals can choose their occupation; skilled or unskilled worker. $i$ denotes the inverse measure of ability, $i_{l}$ denotes the ability of individual $i_{l}$ in country $l$ and $i_{l} \in[0,1]$. Ability is distributed uniformly over the unit interval. The cost of education of individuals $i_{l} \in[0, \gamma]$ to become a skilled worker is zero. When individual $i_{l} \in[\gamma, 1]$ decides to become a skilled worker, he or she has to pay $D\left(i_{l}-\gamma\right)$ unit of good $X$. However, when individual $i_{l}$ does not choose to become a skilled worker, he or she becomes an unskilled worker. Each individual has one unit of labor and supplies one unit of labor inelasticity. When individual $i_{l}>\gamma$ becomes a skilled worker, his or her income becomes $w_{l}-D\left(i_{l}-\gamma\right)$, where $w_{\ddagger}$ denotes the wage rate of a skilled worker in country $l$. However, when individual $i_{l}>\gamma$ becomes an unskilled worker, his or her income is the wage rate of an unskilled worker in country $l, w_{U, l}$. I assume that an individual $\hat{i}_{l}$ is indifferent between becoming a skilled worker and an unskilled worker. Then, the threshold of ability $\hat{i}_{l}$ becomes:

$$
w_{l}-D\left(\hat{i}_{l}-\gamma\right)=w_{U, l}, \quad l \in\{H, F\}
$$

Thus, $\hat{i}_{l} L$ individuals become skilled workers and $\left(1-\hat{i}_{l}\right) L$ individuals become unskilled workers. When the cost of education $D$ approaches to zero, the supply of skilled worker is determined by the demand for skilled worker. This economy is similar to those of Braun (2008) [9] and Haaland and Kind (2008) [11] that consider the homogenous worker. Then, when the cost of education is sufficiently small, our model can be dealt with homogenous workers. On the contrary, when the cost of education $D$ is infinity, the proportion of skilled workers is $\gamma$. This economy is the same as those of Morita (2012) [10] $]^{2}$.

\footnotetext{
${ }^{2}$ This model assumes that education costs are step function to compare this model and Morita (2012) [10].
} 


\subsection{Production}

\subsubsection{Good $X$ Sector}

Production of one unit of good $X$ requires one unit of unskilled workers in both countries. I assume that perfect competition prevails in the good $X$ market and good $X$ can be traded freely. Thus, the wage rate for unskilled workers in both countries equals to unity, that is, $w_{U, H}=w_{U, F}=1$.

\subsubsection{Good $Y$ Sector}

Each firm produces good $Y$ and conducts cost-reducing R\&D investment to decrease their marginal cost of production. Production of good $Y$ requires both skilled and unskilled workers. Production of one unit of good $Y$ requires $\theta$ units of skilled workers and $\alpha\left(k_{l}\right) \in[0, \bar{\alpha}]$ units of unskilled workers in country $l . k_{l}$ denotes the number of skilled workers that is allocated to cost-reducing R\&D investment in country $l$. I assume that $\partial \alpha\left(k_{l}\right) / \partial k_{l}<0$ and $\partial^{2} \alpha\left(k_{l}\right) / \partial k_{l}^{2} \geq 0$. The profit of Firm $H$ is then given by

$$
\pi_{H}=p_{H} y_{H H}+\left(p_{F}-\tau\right) y_{H F}-\left(y_{H H}+y_{H F}\right)\left(\alpha\left(k_{H}\right)+\theta w_{H}\right)-w_{H} k_{H}
$$

where $y_{t, s}$ denotes the output of firm $t$ that is sold in country $s$. Hence, the good $Y$ market clearing conditions in both countries is as follows:

$$
\begin{aligned}
y_{H H}+y_{F H} & =Q_{H} \\
y_{H F}+y_{F F} & =Q_{F}
\end{aligned}
$$

The left hand side of these equations represents the supply of good $Y$ and the right-hand side of these equations represents the demand for good $Y$. Substituting the inverse demand function, (4), (7), and (8) into the profit function (6), I rewrite the profit function of Firm $\mathrm{H}$ as follows:

$$
\begin{aligned}
\pi_{H} & =\left(a-b \frac{y_{H H}+y_{F H}}{L}\right) y_{H H}+\left(a-b \frac{y_{H F}+y_{F F}}{L}-\tau\right) y_{H F} \\
& -\left(y_{H H}+y_{H F}\right)\left(\theta w_{H}+\alpha\left(k_{H}\right)\right)-w_{H} k_{H}
\end{aligned}
$$

Firms maximize their profits by simultaneously choosing the quantity of good $Y$ in the two markets and the level of cost-reducing R\&D investment. Then, the profit maximization of the firms leads to the following levels of output and R\&D investment:

$$
\begin{aligned}
& y_{H H}=\frac{L}{2 b}\left[a-\theta w_{H}-\alpha\left(k_{H}\right)\right]-\frac{y_{F H}}{2} \\
& y_{H F}=\frac{L}{2 b}\left[a-\tau-\theta w_{H}-\alpha\left(k_{H}\right)\right]-\frac{y_{F F}}{2} \\
& w_{H}=-\left(y_{H H}+y_{H F}\right) \alpha^{\prime}\left(k_{H}\right)
\end{aligned}
$$

The left hand side of (12) represents the costs of $R \& D$ investment and the right hand side represents the benefits of R\&D investment. Then, when output level is sufficiently large, the benefits of R\&D investment become large. I assume that the firms take the wage rate of skilled workers and the wage rate of unskilled workers as being constant and that $a-\tau-\theta w_{H}-\alpha\left(k_{H}\right)>0$ holds because this paper focus on the case that there exists international trade. In the same way, the output levels of Firm $F$ are as follows:

$$
\begin{aligned}
& y_{F F}=\frac{L}{2 b}\left[a-\theta w_{F}-\alpha\left(k_{F}\right)\right]-\frac{y_{H F}}{2} \\
& y_{F H}=\frac{L}{2 b}\left[a-\tau-\theta w_{F}-\alpha\left(k_{F}\right)\right]-\frac{y_{H H}}{2}
\end{aligned}
$$

Because I assume that Home and Foreign countries are symmetric and that both firms have the same unit cost function, Firms $H$ and $F$ produce the same output level. Thus, the level of R\&D investment, the wage rate for skilled workers, and the proportion of skilled workers are the same in both countries: $k_{1}=k_{2} \equiv k, w_{H}=w_{S}$ 
$\equiv w$, and $\hat{i}_{H}=\hat{i}_{F}=\hat{i}$. From (10), (11), (13), and (14), the output levels of Firm $H$ and Firm $F$ are given by ${ }^{3}$

$$
\begin{aligned}
& y_{H H}=y_{F F}=\frac{L}{3 b}[a+\tau-\theta w-\alpha(k)] \\
& y_{H F}=y_{F H}=\frac{L}{3 b}[a-2 \tau-\theta w-\alpha(k)]
\end{aligned}
$$

I assume that the parameter $a$ is sufficiently large in order that the output levels of the firms have positive values. Because the purpose of this paper is to investigate the effects of tariffs, I focus on the case in which positive amounts of good $Y$ are traded between the countries.

\subsection{Labor Market Equilibrium Conditions}

The demand for skilled workers is derived from R\&D investment and production of good $Y$. The demand for unskilled workers comes from production of good $X$ and good $Y$. Because the supply of skilled workers is $\hat{i} L$ and that of unskilled workers is $(1-\hat{i}) L$, the labor market equilibrium conditions in country $H$ are given by:

$$
\begin{aligned}
& \hat{i} L=k_{H}+\theta\left(y_{H H}+y_{H F}\right) \\
& (1-\hat{i}) L=x_{H}^{P}+\alpha\left(k_{H}\right)\left(y_{H H}+y_{H F}\right)
\end{aligned}
$$

where $x_{H}^{P}$ denotes the labor demand for the good $X$ sector in country $H$.

\section{Equilibrium}

From (12), (15), and (16), I can obtain the wage rate for skilled workers as follows:

$$
w(k, \tau)=\frac{-\alpha^{\prime}(k) L[2 a-\tau-2 \alpha(k)]}{3 b-2 \theta \alpha^{\prime}(k) L}
$$

When $a$ is sufficiently large or $\tau$ is sufficiently small, the demand size becomes large. Then, an increase in the demand size increases output level and supply of skilled labor increases. Therefore, the wage rate of skilled labor increases. From (5), the threshold of ability $\hat{i}$ is given by

$$
\hat{i}(k, \tau)=\frac{w(k, \tau)-1}{D}+\gamma
$$

Inserting (15), (16) and (20) into the skilled worker equilibrium condition (17), I can obtain the excess labor demand function as follows: ${ }^{4}$

$$
H(k, \tau)=k+\frac{\theta L}{3 b}[2 a-\tau-2 \theta w(k, \tau)-2 \alpha(k)]-\hat{i}(k, \tau) L
$$

Substituting (21) into (20) and (19), the excess labor demand function can be rewritten as follows:

$$
H(k, \tau)=k+\frac{L A(k, \tau)\left(\theta D+\alpha^{\prime}(k) L\right)}{B(k) D}-L\left(\frac{D \gamma-1}{D}\right)
$$

\footnotetext{
${ }^{3}$ In this model, if there are $n$ firms in both countries and they are symmetric, the output levels of firms are given by

$$
y_{H H}=y_{F F}=\frac{L}{b(1+2 n)}[a+n \tau-\theta w-\alpha(k)]
$$$$
y_{H F}=y_{F H}=\frac{L}{3(1+2 n)}[a-2 n \tau-\theta w-\alpha(k)]
$$

Then, the number of firms does not affect the model qualitatively. Therefore, in this paper, we assume that the number of firms is unity for simplicity.

${ }^{4}$ Normally, an excess labor demand function is a relationship between wage and excess labor demand. In this model, the wage rate depends on R\&D level from (19). Therefore, in this model, the excess labor demand function expresses the relationship between R\&D level and excess labor demand.
} 
where $A(k, \tau)=2 a-\tau-2 \alpha(k)>0$ and $B(k)=3 b-2 \alpha^{\prime}(k) L>0$. When $H(k, \tau)=0$, I can obtain the optimal level of R\&D investment. Hereafter, I assume that $\alpha(k)=\bar{\alpha} \mathrm{e}^{-k}$ and $\gamma=\frac{\theta}{\bar{\alpha} L}$ for simplicity. At $k=0$, there is positive excess labor demand when the cost of skilled worker is relatively high, that is $D>\frac{\bar{\alpha} L}{\theta}$, and $\tau<\tau_{1}$ where

$$
\tau_{1}=2(a-\bar{\alpha})-\frac{3 b+2 \theta \bar{\alpha} L}{\bar{\alpha} L}
$$

However, at $k=0$, there is negative excess labor demand when the cost of skilled worker is relatively low, that is $D<\frac{\bar{\alpha} L}{\theta}$, and $\tau<\tau_{1}$. In addition, the slope of the excess labor demand function at $k=0$ is negative when $\tau>\tau_{2}$ where:

$$
\tau_{2}=2(a-\bar{\alpha})+\frac{(3 b+2 \theta \bar{\alpha} L)[D(3 b+2 \theta \bar{\alpha} L)+2 \bar{\alpha} L(\theta D-\bar{\alpha} L)]}{\bar{\alpha} L^{2}\left(3 b+2 \theta^{2} D\right)}
$$

The stability condition of this equilibrium is $\tau<\bar{\tau}$ where

$$
\bar{\tau}=2(a-\bar{\alpha})-\frac{2 \bar{\alpha}(3 b+2 \theta \bar{\alpha} L)}{3 b}
$$

Comparing $\tau_{1}$ with $\tau_{2}$ and $\bar{\tau}$, I can obtain $\tau_{1}<\bar{\tau}<\tau_{2}$ when $3 b>2 \bar{\alpha}^{2} L$ holds ${ }^{5}$. Hereafter, I focus on $\tau<\bar{\tau}$. Then, I can obtain the following proposition (see Appendix for the proof).

PROPOSITION 1. Suppose that $3 b>2 \bar{\alpha}^{2} L$. Then, there exists a unique and a positive level of $R \& D$ investment when $D>\frac{\bar{\alpha} L}{\theta}$ and $\tau_{1}<\tau<\bar{\tau}$ and when $D<\frac{\bar{\alpha} L}{\theta}$ and $\tau<\tau_{1}<\bar{\tau}$.

The excess labor demand function of $H(k, \tau)$ can be depicted in Figure 1(a) and Figure 1(b) when $D>\frac{\bar{\alpha} L}{\theta}$. When $D>\frac{\bar{\alpha} L}{\theta}$ and $\tau<\tau_{1}$ in Figure 1(a), the intercept of $H(k, \tau)$ has a positive value. However, when $D>\frac{\bar{\alpha} L}{\theta}$ and $\tau_{1}<\tau<\bar{\tau}$ in Figure 1(b), the intercept of $H(k, \tau)$ has a negative value. When $D>\frac{\bar{\alpha} L}{\theta}$ and $\tau<\bar{\tau}<\tau_{2}$ in Figure 1(a) and Figure 1(b), the slope of $H(k, \tau)$ at $k=0$ has a positive value. Therefore, when $D>\frac{\bar{\alpha} L}{\theta}$ and $\tau_{1}<\tau<\bar{\tau}$, there exists a unique and positive level of R\&D investment in Figure 1(b).

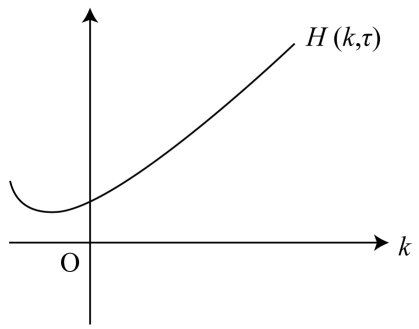

(a)

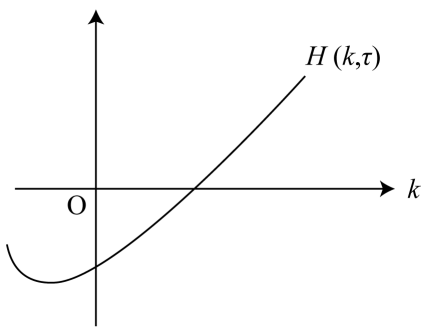

(b)

$$
\text { Figure 1. When } D>\frac{\bar{\alpha} L}{\theta} \text {. (a) } \tau<\tau_{1} \text {; (b) } \tau_{1}<\tau<\bar{\tau} \text {. }
$$

\footnotetext{
${ }^{5}$ When $3 b>2 \bar{\alpha}^{2} L, \quad \tau_{1}<\bar{\tau}<\tau_{2}$ holds. When $3 b<2 \bar{\alpha}^{2} L$ holds, $\bar{\tau}<\tau_{1}<\tau_{2}$. I can obtain the same result whether this inequality holds or not.
} 
When the cost of education, $D$, is sufficiently small, the excess labor demand function of $H(k, \tau)$ can be depicted in Figure 2(a) and Figure 2(b). When $D<\frac{\bar{\alpha} L}{\theta}$ and $\tau<\tau_{1}$ in Figure 2(a), the intercept of $H(k, \tau)$ has a negative value. However, when $D<\frac{\bar{\alpha} L}{\theta}$ and $\tau_{1}<\tau<\bar{\tau}$ in Figure 2(b), the intercept of $H(k, \tau)$ has a positive value. When $D<\frac{\bar{\alpha} L}{\theta}$ and $\tau<\bar{\tau}<\tau_{2}$ in Figure 2(a) and Figure 2(b), the slope of $H(k, \tau)$ at $k=0$ has a positive value. Therefore, when $D<\frac{\bar{\alpha} L}{\theta}$ and $\tau<\tau_{1}$, there exists a unique and positive level of R\&D investment in Figure 2(a).

The relationship between the tariff rate and the level of R\&D investment is given by following proposition (see Appendix for the proof).

PROPOSITION 2. When $D>\frac{\bar{\alpha} L}{\theta}$ and $\tau>\tau_{1}$, a decrease in the tariff rate decreases $R \& D$ investment. When $D<\frac{\bar{\alpha} L}{\theta}$ and $\tau<\tau_{1}$, a decrease in the tariff rate increases $R \& D$ investment.

Figure 3 describes the case when the cost of education is sufficiently high, that is, $D>\frac{\bar{\alpha} L}{\theta}$. Then, a decrease in the tariff rate rotates the excess labor demand function of $H(k, \tau)$ around $k=\ln \frac{\bar{\alpha} L}{\theta D}<0$ in a counterclockwise direction. Therefore, a decrease in the tariff rate decreases the level of R\&D investment. However, Figure 4 describes the case when the cost of education is sufficiently low. Then, a decrease in the tariff rate rotates the excess labor demand function of $H(k, \tau)$ around $k=\ln \frac{\bar{\alpha} L}{\theta D}>0$ in a counterclockwise direction. Therefore, a decrease in the tariff rate increases the level of R\&D investment.

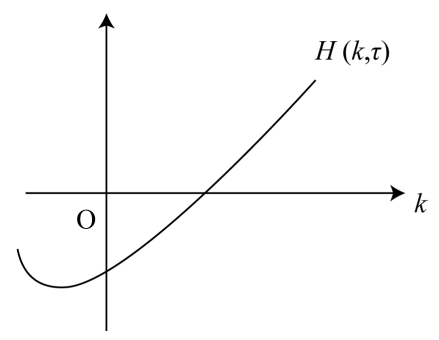

(a)

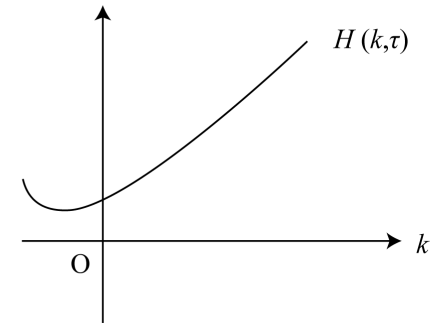

(b)

Figure 2. $D<\frac{\alpha L}{\theta}$. (a) $\tau<\tau_{1}$; (b) $\tau_{1}<\tau<\bar{\tau}$.

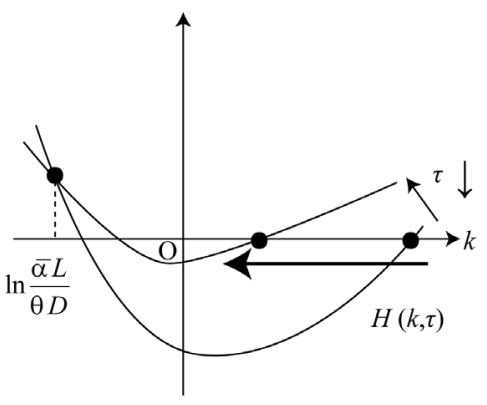

Figure 3. $D>\frac{\bar{\alpha} L}{\theta}$. 


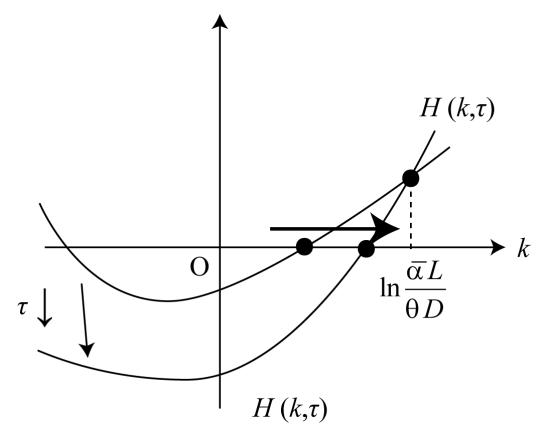

Figure 4. $D<\frac{\bar{\alpha} L}{\theta}$.

I explain Proposition 2 intuitively. Differentiating (21) with respect to $\tau$, we can obtain the following equation:

$$
\begin{aligned}
\frac{\partial H(k, \tau)}{\partial \tau} & =\frac{\partial H(k, \tau)}{\partial \tau}+\frac{\partial H(k, \tau)}{\partial w(k, \tau)} \frac{\partial w(k, \tau)}{\partial \tau}+\frac{\partial H(k, \tau)}{\partial \hat{i}(k, \tau)} \frac{\partial \hat{i}(k, \tau)}{\partial \tau} \\
& =-\frac{\theta L}{3 b}-\frac{2 \theta^{2} L}{3 b} \frac{\partial w(k, \tau)}{\partial \tau}-\frac{L}{D} \frac{\partial w(k, \tau)}{\partial \tau}
\end{aligned}
$$

where $\frac{\partial w(k, \tau)}{\partial \tau}$ is negative from (19). The first term is negative and I dub this effect as trade effect. This effect is a direct effect. The second and the third terms are positive and I dub these effects as wage effect, and occupational choice effect, respectively. Wage effect is an indirect effect on the excess labor demand. Firstly, trade effect reduces cost-reducing R\&D investment when tariff rate decreases. When the tariff rate decreases, both firms increase their output levels and the demand for skilled worker increases. Then, the excess labor demand of skilled labor increases. Therefore, the number of skilled worker allocated to R\&D sector decreases and $R \& D$ investment decreases. Secondly, wage effect raises cost-reducing $R \& D$ investment when the tariff rate decreases. When the tariff rate decreases, labor demand increases and the wage rate of skilled worker increases. Then, the firms reduce the output level and the demand for skilled worker decreases. Hence, from the labor market equilibrium condition of skilled worker, labor supply of skilled worker for R\&D investment increases. However, wage effect is smaller than trade effect ${ }^{6}$. Finally, occupational choice effect increases the costreducing R\&D investment when the tariff rate decreases. When the tariff rate decreases, both firms increase their output levels. Then, the demand for skilled workers increases and the wage rate of skilled workers increases. Consequently, the income of skilled workers increases and the supply of skilled workers increases. Therefore, the number of skilled workers hired in $R \& D$ activities increases and the demand for skilled worker increases.

When the cost of education is sufficiently high, individuals are less likely to become skilled workers. Then, the effect of occupational choice effect becomes small. Therefore, the sum of wage effect and occupational choice effect is smaller than trade effect and a decrease in the tariff rate decreases the level of R\&D investment. On the other hand, when the cost of education is sufficiently low, individuals easily become skilled workers. Then, the effect of occupational choice effect becomes large. Therefore, the sum of wage effect and occupational choice effect overcome trade effect and a decrease in the tariff rate raises the level of R\&D investment.

The next proposition shows the relationship between the tariff rate and the output level of good $Y$ (see Appendix for the proof).

PROPOSITION 3. When $D<\frac{\bar{\alpha} L}{\theta}$, a decrease in the tariff rate increases the output level.

${ }^{6}$ The sum of trade effect and wage effect is negative because

$$
-\frac{\theta L}{3 b}-\frac{2 \theta^{2} L}{3 b} \frac{\partial w(k, \tau)}{\partial \tau}=-\frac{\theta L}{B(k)}<0
$$

Then, when the costs of education $D$ approach to infinity, occupational choice effect becomes zero and (26) becomes negative. In this case, the results of this model are same as Morita (2012) [10]. 
When the tariff rate decreases, there is a direct effect and an indirect effect. The direct effect is that when the tariff rate decreases, the cost of exports decreases and the firms increase their exports and output levels. The indirect effect is that when the tariff rate decreases, the level of R\&D investment changes. An increase in the level of R\&D investment raises productivity and the output level. A decrease in the level of R\&D investment reduces productivity and the output level. Therefore, when the cost of education is sufficiently low, a decrease in the tariff rate increases the level of R\&D investment as shown in Proposition 2 and increases the output level. However, when the cost of education is sufficiently high, a decrease in the tariff rate decreases the level of R\&D investment. Then, the direct effect is opposite to the indirect effect. The relationship between the tariff rate and the output level is ambiguous.

When the tariff rate decreases, does the wage rate of skilled workers increase and the number of skilled workers increase? As for the relationship between the tariff rate and the number of skilled workers, I can obtain the following proposition.

PROPOSITION 4. When $D>\frac{\bar{\alpha} L}{\theta}$, a decrease in the tariff rate increases the wage gap between skilled and unskilled workers and increases the number of skilled workers.

Proof. The effect of the tariff rate on the wage rate of skilled workers can be divided into two parts: direct effect and indirect effect. Differentiating (19) with respect to $\tau$, I obtain the following equation:

$$
\frac{\partial w(k, \tau)}{\partial \tau}=\frac{\partial w(k, \tau)}{\partial \tau}+\frac{\partial w(k, \tau)}{\partial k} \frac{\partial k}{\partial \tau}=-\frac{\bar{\alpha} \mathrm{e}^{-k} L}{B(k)}+\frac{\partial w}{\partial k} \frac{\partial k}{\partial \tau}
$$

The first term of (27) has a negative value. From the stability condition, $\frac{\partial w(k, \tau)}{\partial k}<0$. When $D>\frac{\bar{\alpha} L}{\theta}$ holds, $\frac{\partial k}{\partial \tau}>0$ as shown in Proposition 2. Then, the second term of (27) has a negative value and $\frac{\partial w(k, \tau)}{\partial \tau}<0$. Therefore, when the cost of education is sufficiently high, a decrease in the tariff rate increases the wage rate of skilled workers. When $D<\frac{\bar{\alpha} L}{\theta}$ holds, $\frac{\partial k}{\partial \tau}<0$ as shown in Proposition 2. Then, the second term of (27) has a positive value and the sign of $\frac{\partial w(k, \tau)}{\partial \tau}$ is ambiguous. Therefore, when the cost of education is sufficiently low, the relationship between the tariff rate and the wage rate of skilled workers is ambiguous.

I explain the above proposition intuitively. There is a direct effect and an indirect effect. The first term of (27) represents the direct effect and the second term represents the indirect effect. The direct effect is that when the tariff rate decreases given the level of R\&D investment, the cost of exports decreases, and both firms increase their volume of exports and increase their output level. Then, the demand for skilled workers increases. Hence, the direct effect has a positive effect on the wage rate of skilled workers. The indirect effect is that the level of R\&D investment affects the price of good $Y$. When the cost of education is sufficiently high, a decrease in the tariff rate decreases the level of R\&D investment from Proposition 2, reduces the productivity of good $Y$, and the relative price of good $Y$ increases. Hence, the demand for skilled workers increases relatively and the indirect effect also has a positive effect. Therefore, when the cost of education is sufficiently high, a decrease in the tariff rate increases the wage rate of skilled workers. When the cost of education is sufficiently small, a decrease in the tariff rate increases the level of R\&D investment from Proposition 2 and decreases the cost of good $Y$. Then, the relative price of good $Y$ decreases, the demand for unskilled workers increases, and the wage rate of skilled workers decreases relatively. Therefore, when the cost of education is sufficiently small, the indirect effect has a negative effect. Hence, the relationship between the tariff rate and the wage rate of skilled workers is ambiguous when the cost of education is sufficiently small.

\section{Conclusions}

In this paper, I construct a two-country model in which abilities of individuals are heterogeneous and oligopolistic firms produce goods and undertake cost-reducing R\&D investment. There are two main results. The first result is the relationship between trade liberalization and the wage gap. Trade liberalization increases the wage gap 
between skilled workers and unskilled workers when the cost of education is sufficiently high. When the cost of education is sufficiently low, the relationship between trade liberalization and the wage rate of skilled workers is ambiguous.

The second result is the relationship between trade liberalization and the level of $R \& D$ investment. This paper investigates the effects of trade liberalization on $\mathrm{R} \& \mathrm{D}$ investment. There are three effects: trade effect, wage effect, and occupational choice effect. Trade effect is a negative effect on R\&D investment when tariff rates decrease. Wage effect and occupational choice effect are positive effects on the R\&D investment when tariff rates decrease. The second result is separated into two cases. First, when the cost of education is sufficiently low, the wage effect plus the occupational choice effect dominate the trade effect and a decrease in the tariff rate increases cost-reducing R\&D investment. This result is same as Braun (2008) [9] and Haaland and Kind (2008) [11]. Second, when the cost of education is sufficiently high, the trade effect dominate the wage effect plus the occupational choice effect and a decrease in the tariff rate decreases cost-reducing R\&D investment. This case is similar to Morita (2012). Therefore, the cost of education determines the effects of trade liberalization on the level of R\&D investment.

Comparing this paper and Morita (2012) [10], this paper provided a long-term analysis and Morita (2012) [10] provided a short-term analysis. In the short term, it is difficult for workers to acquire skills. Therefore, in the short term, the ratio of skilled workers to unskilled workers is constant. However, the ratio of skilled workers to unskilled workers is endogenous. This paper and Morita (2012) [10] concluded that trade liberalization decreases the level of R\&D investment in the short term and may increases the level of R\&D investment in the long term.

\section{Acknowledgements}

I am very grateful to Koichi Futagami for his valuable help. I would also like to thank Xiao Chen, Masahisa Fujita, Taiji Furusawa, Takeo Hori, Jota Ishikawa, Yoshinori Kurokawa, Toshihiro Matsumura, Tomoya Mori, Se-il Mun, Takayuki Ogawa, Rhoji Ohdoi, Ryosuke Okamoto, Makoto Okamura, Yoshifumi Okawa, Yoshiyasu Ono, Tsuyoshi Toshimitsu, and seminar participants at Chuo University, Kwansei Gakuin University, Kyoto University, Osaka University, and Osaka City University, Osaka Prefecture University, at the 23rd Annual Meeting of the Applied Regional Science Conference at Yamagata University, the 4th Conference of Macroeconomics for Young Professionals, the 2010 Japanese Economic Association Spring Meeting at Chiba University, Asia Pacific Trade Seminars (2010), and Hitotsubashi COE Trade Workshop for Young Researchers. I acknowledge the financial support of the MEXT Grant-in-Aid for Young Scientists (B).

\section{References}

[1] Wacziarg, R. and Welch, K.H. (2008) Trade Liberalization and Growth: New Evidence. The World Bank Economic Review, 22, 187-231. http://dx.doi.org/10.1093/wber/lhn007

[2] Acemoglu, D. (2002) Technical Change, Inequality, and the Labor Market. Journal of Economic Literature, 40, 7-72. http://dx.doi.org/10.1257/jel.40.1.7

[3] Sachs, J.D. and Warner, A. (1995) Economic Reform and the Process of Global Integration. Brookings Papers on Economic Activity, 1, 1-95. http://dx.doi.org/10.2307/2534573

[4] Funk, M. (2003) The Effects of Trade on Research and Development. Open Economies Review, 14, 29-42. http://dx.doi.org/10.1023/A:1021247218110

[5] Scherer, F.M. and Keun, H. (1992) R\&D Reactions to High-Technology Import Competition. Review of Economics and Statistics, 74, 202-212. http://dx.doi.org/10.2307/2109651

[6] Wood, A. (1994) North-South Trade, Employment and Inequality: Changing Fortunes in a Skill Driven World. Clarendon Press, Oxford.

[7] Leamer, E.E. (1996) In Search of Stolper-Samuelson Effects on U.S. Wages. NBER Working Paper No. 5427.

[8] Kurokawa, Y. (2010) Variety-Skill Complementarity: A Simple Resolution of the Trade-Wage Inequality Anomaly. Economic Theory, 46, 297-325.

[9] Braun, S. (2008) Economic Integration, Process and Product Innovation, and Relative Skill Demand. Review of International Economics, 16, 864-873.

[10] Morita, T. (2012) Cost-Reducing R\&D Investment, Labor Market, and Trade. Review of International Economics, 20, 821-827. http://dx.doi.org/10.1111/j.1467-9396.2012.01057.x 
[11] Haaland, J.I. and Kind, H.J. (2008) R\&D Policies, Trade and Process Innovation. Journal of International Economics, 74, 170-187. http://dx.doi.org/10.1016/j.jinteco.2007.04.001

[12] Long, N.V., Raff, H. and Stähler, F. (2011) Innovation and Trade with Heterogeneous Firms. Journal of International Economics, 84, 149-159. http://dx.doi.org/10.1016/j.jinteco.2011.03.008

[13] Costantini, J.A. and Melitz, M.J. (2008) The Dynamics of Firm-Level Adjustment to Trade Liberalization. The Organization of Firms in a Global Economy, Harvard University Press, Cambridge, 107-141.

[14] Atkeson, A. and Burstein, A. (2010) Innovation, Firm Dynamics, and International Trade. Journal of Political Economy, 118, 433-484. http://dx.doi.org/10.1086/653690 


\section{Appendix}

\section{A.1. Proof of Proposition 1}

This proof can be solved in four steps. In the first step, I analyze the value of $H(k, \tau)$ at $k=0$. The Second step investigates the value of $H(k, \tau)$ when $k$ approaches to infinity. The third step examines the gradient of $H(k, \tau)$ at $k=0$. Finally, the fourth step shows that the equilibrium is stable when $\tau \leq \bar{\tau}$. In addition, I show that $\tau_{1}<\bar{\tau}<\tau_{2}$.

Firststep : Investigating the value of $H(0, \tau)$, I obtain the following lemma.

LEMMA 1. If $\tau>\tau_{1}$ and $D>\frac{\bar{\alpha} L}{\theta}$, there is excess labor supply when $k=0$. However, if $\tau>\tau_{1}$ and $D<\frac{\bar{\alpha} L}{\theta}$, there is excess labor demand when $k=0$.

Proof. Remember that I assumed that $\alpha(k)=\bar{\alpha} \mathrm{e}^{-k}$ and $\gamma=\frac{\theta}{\bar{\alpha} L}$. The intercept of $H(k, \tau)$ is given by:

$$
H(0, \tau)=\frac{\theta D-\bar{\alpha} L}{\bar{\alpha} D(3 b+2 \theta \bar{\alpha} L)}[\bar{\alpha} L(2 a-\tau-2 \bar{\alpha})-3 b-2 \theta \bar{\alpha} L]
$$

When $\tau>\tau_{1}$ and $D>\frac{\bar{\alpha} L}{\theta}$, I obtain:

$$
H(0, \tau)<\frac{\theta D-\bar{\alpha} L}{\bar{\alpha} D(3 b+2 \theta \bar{\alpha} L)}\left[\bar{\alpha} L\left(2 a-\tau_{1}-2 \bar{\alpha}\right)-3 b-2 \theta \bar{\alpha} L\right]=0
$$

However, when $\tau>\tau_{1}$ and $D<\frac{\bar{\alpha} L}{\theta}$, the intercept of $H(0, \tau)$ has a positive value.

Secondstep : The second step investigates the value of $H(k, \tau)$ when $k$ approaches infinity. When $k$ approaches infinity, the limiting value of $H(k, \tau)$ is as follows:

$$
\begin{aligned}
\lim _{k \rightarrow \infty} H(k, \tau) & =\lim _{k \rightarrow \infty}\left(k+\frac{L A(k, \tau)\left(\theta D+\alpha^{\prime}(k) L\right)}{B(k) D}-L\left(\frac{D \gamma-1}{D}\right)\right) \\
& =\lim _{k \rightarrow \infty} k+\left[\frac{L(2 a-\tau) \theta D}{3 b D}-L\left(\frac{D \gamma-1}{D}\right)\right]=\infty .
\end{aligned}
$$

Therefore, when R\&D investment of $k$ approaches infinity, the excess labor demand increases without bound.

Thirdstep : In the third step, I examine the shape of the excess demand function, $H(k, \tau)$. Then, I obtain the following lemma.

LEMMA 2. When $\tau>\tau_{2}$, the slope of $H(k, \tau)$ at $k=0$ is negative.

Proof. Differentiating $H(k, \tau)$ with respect to $k$, I can obtain the following:

$$
\frac{\partial H(k, \tau)}{\partial k}=1+\frac{\bar{\alpha} \mathrm{e}^{-k} L g(k, \tau)}{D B(k)^{2}}
$$

where

$$
g(k, \tau) \equiv 2\left(\theta D-\bar{\alpha} \mathrm{e}^{-k} L\right) B(k)+L A(k, \tau)\left(3 b+2 \theta^{2} D\right)
$$

Differentiating $g(k, \tau)$ with respect to $k$, I can obtain the following:

$$
\begin{aligned}
\frac{\partial g(k, \tau)}{\partial k} & =2 \bar{\alpha} \mathrm{e}^{-k} L B(k)-4\left(\theta D-\bar{\alpha} \mathrm{e}^{-k} L\right) \theta \bar{\alpha} \mathrm{e}^{-k} L+2 L\left(3 b+2 \theta^{2} D\right) \bar{\alpha} \mathrm{e}^{-k} \\
& =4 \bar{\alpha} \mathrm{e}^{-k} L\left(3 b+2 \theta \bar{\alpha} \mathrm{e}^{-k} L\right)>0
\end{aligned}
$$


Therefore, $g(k, \tau)$ is increasing function of $k$. Then, when $k$ is sufficiently small, the sign of (A.3) may become negative. However, when $k$ is sufficiently large, the sign of (A.3) is positive. Then, the sign of (A.3) changes once.

When $k=0$ and $\tau>\tau_{2}$, the slope of the excess demand function is given by

$$
\begin{aligned}
\left.\frac{\partial H(k, \tau)}{\partial k}\right|_{k=0} & =\frac{\left[D B(0)^{2}+\bar{\alpha} L\left\{2(\theta D-\bar{\alpha} L) B(0)+L(2 a-\tau-2 \bar{\alpha})\left(3 b+2 \theta^{2} D\right)\right\}\right]}{D B(0)^{2}} \\
& <\frac{\left[D B(0)^{2}+\bar{\alpha} L\left\{2(\theta D-\bar{\alpha} L) B(0)+L\left(2 a-\tau_{2}-2 \bar{\alpha}\right)\left(3 b+2 \theta^{2} D\right)\right\}\right]}{D B(0)^{2}}=0 .
\end{aligned}
$$

Thus, when $\tau>\tau_{2}$, the value of $\left.\frac{\partial H(k, \tau)}{\partial k}\right|_{k=0}$ has a negative value.

Fourthstep : In this step, I show that the equilibrium is stable when $\tau \leq \bar{\tau}$ and $\tau_{1}<\bar{\tau}<\tau_{2}$. To analyze the stability condition, I differentiate the wage rate with respect to the level of R\&D investment.

$$
\begin{aligned}
\frac{\partial w(k, \tau)}{\partial k} & =\frac{1}{B(k)^{2}}\left[\left\{-\bar{\alpha} \mathrm{e}^{-k} L A(k, \tau)+2 \bar{\alpha} \mathrm{e}^{-k} L \bar{\alpha} \mathrm{e}^{-k}\right\} B(k)-\bar{\alpha} \mathrm{e}^{-k} L A(k, \tau)\left(-2 \theta \bar{\alpha} \mathrm{e}^{-k} L\right)\right] \\
& =-\frac{\bar{\alpha} \mathrm{e}^{-k} L}{B(k)^{2}} C(k, \tau),
\end{aligned}
$$

where

$$
C(k, \tau) \equiv 3 b A(k, \tau)-2 \bar{\alpha} \mathrm{e}^{-k} B(k)
$$

When the equilibrium is stable, the excess labor demand curve is downward sloping against the wage rate of skilled workers, that is $\frac{\partial H(k, \tau)}{\partial w(k, \tau)}<0$. Then, because the excess labor demand function is an increasing function of $k$, that is $\frac{\partial H(k, \tau)}{\partial k}>0$, the stability condition is $\frac{\partial w(k, \tau)}{\partial k}<0$, that is $C(k, \tau)>0$. When the stability condition is satisfied and there exists excess labor demand (supply), the wage rate of skilled worker increases (decreases). Then, the level of R\&D investment decreases (increases). Investigating the sign of $C(k, \tau)$, I obtain the following lemma.

LEMMA 3. When $\tau \leq \bar{\tau}$, the equilibrium is stable.

Proof. The stability condition is $\frac{\partial w(k, \tau)}{\partial k}<0$, that is $C(k, \tau)>0$. Then,

$$
\begin{aligned}
C(k, \tau) & =3 b\left(2 a-\tau 2 \bar{\alpha} \mathrm{e}^{-k}\right)-2 \bar{\alpha} \mathrm{e}^{-k}\left(3 b+2 \theta \bar{\alpha} \mathrm{e}^{-k} L\right) \\
& \geq 3 b(2 a-\tau-2 \bar{\alpha})-2 \bar{\alpha}(3 b+2 \theta \bar{\alpha} L) \\
& \geq 3 b(2 a-\tau-2 \bar{\alpha})-2 \bar{\alpha}(3 b+2 \theta \bar{\alpha} L)=0 .
\end{aligned}
$$

Then, when $\tau<\bar{\tau}, C(k, \tau)$ has a positive value.

Therefore, when $\tau<\bar{\tau}, \frac{\partial w(k, \tau)}{\partial k}$ has a negative value and the equilibrium is stable. Next, I compare $\bar{\tau}$ to $\tau_{1}$ and to $\tau_{2}$.

$$
\begin{aligned}
\bar{\tau}-\tau_{1} & =2(a-\bar{\alpha})-\frac{2 \bar{\alpha}(3 b+2 \theta \bar{\alpha} L)}{3 b}-2(a-\bar{\alpha})+\frac{3 b+2 \theta \bar{\alpha} L}{\bar{\alpha} L} \\
& =\frac{3 b+2 \theta \bar{\alpha} L}{3 b \bar{\alpha} L}\left[3 b-2 \bar{\alpha}^{2} L\right]>0
\end{aligned}
$$


because $3 b>2 \bar{\alpha}^{2} L$. Then, $\bar{\tau}$ is larger than $\tau_{1}$.

$$
\begin{aligned}
\tau_{2}-\bar{\tau} & =2(a-\bar{\alpha})+\frac{(3 b+2 \theta \bar{\alpha} L)[D(3 b+2 \theta \bar{\alpha} L)+2 \bar{\alpha} L(\theta D-\bar{\alpha} L)]}{\bar{\alpha} L^{2}\left(3 b+2 \theta^{2} D\right)}-2(a-\bar{\alpha})+\frac{3 b+2 \theta \bar{\alpha} L}{\bar{\alpha} L} \\
& =\frac{3 b+2 \theta \bar{\alpha} L}{3 b \bar{\alpha} L^{2}\left(3 b+2 \theta^{2} D\right)}\left[3 b D(3 b+2 \theta \bar{\alpha} L)+6 b \bar{\alpha} L \theta D+4 \theta \bar{\alpha}^{3} L^{3}\right]>0 .
\end{aligned}
$$

Then, $\tau_{2}$ is larger than $\bar{\tau}$. Therefore, I can obtain $\tau_{1}<\bar{\tau}<\tau_{2}$.

Summarizing the above four steps, there exists a unique and positive level of $R \& D$ investment when $D>\frac{\bar{\alpha} L}{\theta}$ and $\tau_{1}<\tau<\bar{\tau}$, and when $D<\frac{\bar{\alpha} L}{\theta}$ and $\tau<\tau_{1}<\bar{\tau}$.

\section{A.2. Proof of Proposition 2}

Differentiating $H(k, \tau)$ with respect to $\tau$, I can obtain

$$
\frac{\partial H(k, \tau)}{\partial \tau}=\frac{L\left(\theta D-\bar{\alpha} \mathrm{e}^{-k} L\right)}{B(k) D} \frac{\partial A(k, \tau)}{\partial \tau}=-\frac{L\left(\theta D-\bar{\alpha} \mathrm{e}^{-k} L\right)}{B(k) D}
$$

Then, when $k>\log \left(\frac{\bar{\alpha} L}{\theta D}\right), \frac{\partial H(k, \tau)}{\partial \tau}$ has a negative value. However, when $k<\log \left(\frac{\bar{\alpha} L}{\theta D}\right), \frac{\partial H(k, \tau)}{\partial \tau}$ has a positive value. Therefore, when $D>\frac{\bar{\alpha} L}{\theta}$, a decrease in the tariff rate rotates the excess labor demand function around $k=\ln \frac{\bar{\alpha} L}{\theta D}<0$ in a counterclockwise direction. However, when $D<\frac{\bar{\alpha} L}{\theta}$, a decrease in the tariff rate rotates the excess labor demand function around $k=\ln \frac{\bar{\alpha} L}{\theta D}>0$ in a counterclockwise direction.

\section{A.3. Proof of Proposition 3}

From (19), I can obtain the output level of Firm $H$ as follows:

$$
y_{H H}+y_{H F}=\frac{L A(k, \tau)}{B(k)}
$$

Differentiating (A.14) with respect to $\tau$, I can obtain:

$$
\frac{\partial\left(y_{H H}+y_{H F}\right)}{\partial \tau}=\frac{2 \bar{\alpha} \mathrm{e}^{-k} L}{B(k)^{2}}[B(k)+\theta L A(k, \tau)] \frac{\partial k}{\partial \tau}-\frac{L}{B(k)}
$$

The second term represents the direct effect and the first term represents the indirect effect when the tariff rate changes. The second term of this derivative has a negative value for all values of education cost, $D$. The value of the first term in parentheses has a positive value because $A(k, \tau)>0$ and $B(k)>0$. When $D<\frac{\bar{\alpha} L}{\theta}, \frac{\partial k}{\partial \tau}$ is negative as shown in Proposition 2. Therefore, the sign of $\frac{\partial\left(y_{H H}+y_{H F}\right)}{\partial \tau}$ has a negative value. Hence, a decrease in the tariff rate increases the output level when the cost of education is sufficiently low. However, when $D>\frac{\bar{\alpha} L}{\theta}, \frac{\partial k}{\partial \tau}$ is positive from Proposition 2. Then, the first term has a positive value. Therefore, the sign of $\frac{\partial\left(y_{H H}+y_{H F}\right)}{\partial \tau}$ is ambiguous. Hence, when the cost of education is sufficiently high, the relationship between the tariff rate and the output level is ambiguous. 
Scientific Research Publishing (SCIRP) is one of the largest Open Access journal publishers. It is currently publishing more than 200 open access, online, peer-reviewed journals covering a wide range of academic disciplines. SCIRP serves the worldwide academic communities and contributes to the progress and application of science with its publication.

Other selected journals from SCIRP are listed as below. Submit your manuscript to us via either submit@scirp.org or Online Submission Portal.
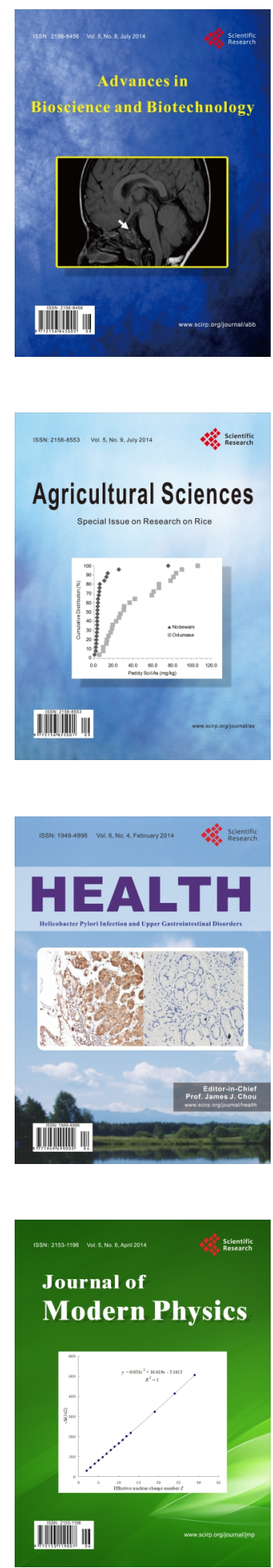
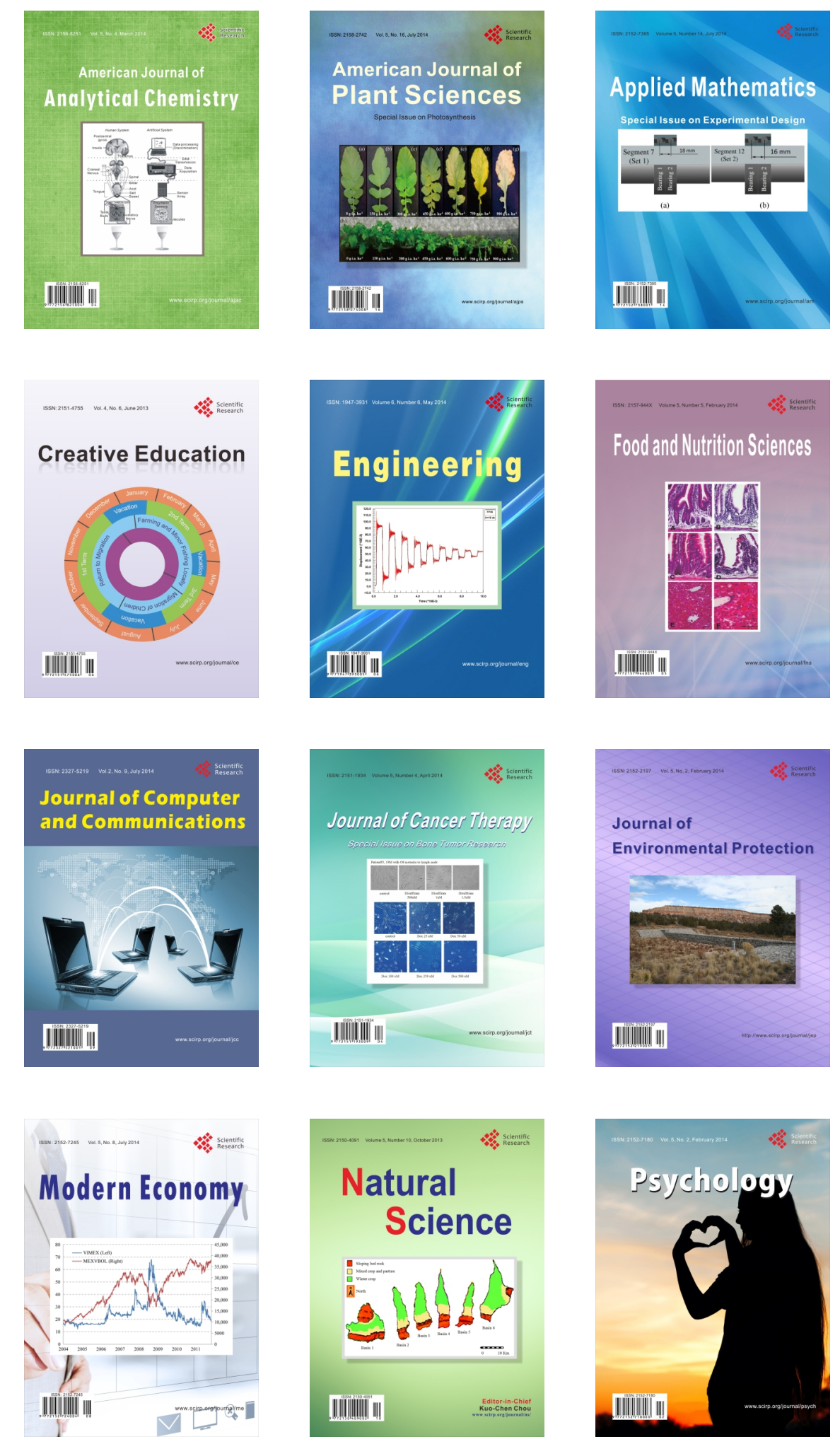